\title{
Analysis of Marker Expression in Porcine Cell Lines Derived from Blastocysts Produced In Vitro and In Vivo
}

\author{
Irena VACKOVA ${ }^{1,2)}$, Zora NOVAKOVA ${ }^{1,2)}$, Vladimir KRYLOV ${ }^{1)}$, Konosuke OKADA ${ }^{1,3)}$, \\ Tomas KOTT ${ }^{1,2)}$, Helena FULKA ${ }^{1,2)}$ and Jan MOTLIK ${ }^{2,4)}$ \\ ${ }^{1)}$ Institute of Animal Science, CS-104 00 Prague, ${ }^{2)}$ Center for Cell Therapy and Tissue Repair, CS-150 06 Prague, \\ Czech Republic, ${ }^{3)}$ Nippon Veterinary and Life Science University, Tokyo 180-0023, Japan and ${ }^{4)}$ Institute of Animal \\ Physiology and Genetics, Czech Academy of Science, CS-277 21 Libechov, Czech Republic
}

\begin{abstract}
The present study was designed to extensively characterize cell lines derived from porcine blastocysts by several methodical approaches, including morphological observation, cytogenetic analysis, estimation of alkaline phosphatase activity and detection of specific marker expression at the mRNA/protein level. A comparison was made between the properties of cell lines isolated from in vivo- and in vitro-obtained blastocysts. Our results showed that $57.1 \%$ of the in vivo-obtained blastocysts attached to the feeder layer and that 33.3\% of them started to grow in a monolayer. The percentage of attached in vitro-produced blastocysts was lower (24.6\%), and only $6.9 \%$ of them started to grow. Outgrowths from the in vitro-produced blastocysts formed mainly trophectoderm or epithelial-like monolayer, whereas the in vivo-obtained blastocysts formed heterogeneous outgrowths that also contained cells with embryonic stem (ES)-like morphology. Detailed analyses showed that the primary outgrowths with ES-like morphology expressed the pluripotency markers OCT-4 and NANOG and revealed intensive alkaline phosphatase staining, while they did not express markers of differentiation. The majority of passaged cells, including those with ESlike morphology, lacked OCT-4 protein and revealed expression of specific differentiation markers (CYTOKERATIN 18, LAMINS A/C, TRANSFERRIN, $\alpha$-FETOPROTEIN and GATA-4), although they still expressed NANOG and exhibited weak alkaline phosphatase activity. Moreover, these cells spontaneously differentiated into neural, fibroblast or epithelial-like cells, even in the presence of leukaemia inhibitory factor. Our results show that complex analysis of markers of pluripotency as well as differentiation markers is necessary for proper interpretation of data in porcine embryonic stem cell studies.
\end{abstract}

Key words: Blastocyst, In vitro, In vivo, Pig, Stem cells

(J. Reprod. Dev. 57: 594-603, 2011)

$\mathbf{T}$ he successful isolation and characterization of mouse ES (embryonic stem) cell lines $[1,2]$ has resulted in considerable efforts aimed to establish ES cell lines in other species, including humans. ES cells are unique cells with the capacity for unlimited proliferation without differentiation under optimal in vitro conditions and with broad differentiation plasticity in vivo and in vitro. When introduced into blastocysts, they can contribute to all cell lineages, including the germline [3]. Validated ES cells with all of these properties have been isolated only in the mouse and rat [4], as no germline chimeras have been reported in other mammals. The absence of cell lines capable of generating germline chimeras limits the possibility of using farm animal ES cells as tools for genetic manipulation [5]. Since 1998, when pluripotent human ES cell lines were established [6], ES cell research has been mainly focused on therapeutic use in human medicine. Before stem cell therapies are introduced into human medicine, it will be necessary to develop and verify the safety and effectiveness of these methods in a convenient animal model. The pig, which is an outbred, largesize animal with obvious morphological, anatomical, physiological

Received: December 7, 2010

Accepted: May 17, 2011

Published online in J-STAGE: June 17, 2011

(C2011 by the Society for Reproduction and Development

Correspondence: I Vackova (e-mail: ivackova@seznam.cz) and immunological similarities to humans, is attractive as a clinical model for the human. Therefore, pig ES cells are promising candidates for preclinical testing of regenerative cell therapies.

Within the last three decades, many reports on porcine ES or ESlike cell lines have been published. Nevertheless, none of these studies fulfilled the requirements of real ES cell lines based on mouse ES cell standards, in particular, germline chimera generation and unlimited self-renewal in an undifferentiated state [7, 8]. For ES cell line generation, the majority of research teams used blastocysts derived in vivo, which were shown to be superior to their in vitro-produced counterparts [9]. However, the use of in vivoderived blastocysts (in vivo blastocysts) as starting material for isolation of ES cells is expensive and laborious. Therefore, for the practical and extensive utilization of porcine ES cell lines as an animal model for human stem cell therapies, it would be advisable to improve the procedures for derivation of ES cells from in vitro-produced embryos.

The present study was undertaken to compare and characterize cell lines isolated from porcine in vivo- and in vitro-produced blastocysts (IVP blastocysts). To achieve this aim, immunocytochemical studies were performed using a panel of antibodies specific to known antigens associated not only with pluripotency but also with different phenotypes. Furthermore, morphological observation, cytogenetic analysis, estimation of 
alkaline phosphatase activity and assessment of pluripotency marker expression including telomerase were performed.

\section{Material and Methods}

\section{Chemicals}

Unless otherwise stated, all chemicals were purchased from Sigma-Aldrich (Sigma-Aldrich, St. Louis, MO, USA).

\section{Blastocyst collection, inner cell mass isolation and cultivation}

Porcine blastocysts produced in vivo were obtained after slaughtering experimental miniature pigs bred at the Institute of Animal Physiology and Genetics, Libechov [10]. The uterine horns of mated gilts (4-5 days) were removed post mortem and flushed with PBS plus $10 \%$ foetal bovine serum (FBS; Invitrogen, Carlsbad, CA, USA). Flushed embryos were divided into three groups: (i) expanded blastocysts, (ii) nonexpanded blastocysts and (iii) morulae. Morulae or nonexpanded blastocysts were cultivated until expansion or hatching for 12-24 h in M199 medium supplemented with $10 \% \mathrm{FBS}$ at $38.5 \mathrm{C}$ with $5 \% \mathrm{CO}_{2}$ in a humidified atmosphere. IVP blastocysts were obtained by in vitro fertilization (IVF), intracytoplasmic sperm injection (ICSI) and parthenogenetic activation (PA) of in vitro-matured oocytes. Immature oocytes were obtained from prepubertal gilts (slaughter weight $100-110 \mathrm{~kg}$ ) of commercial breeds at a local slaughterhouse. Oocyte collection and maturation, sperm preparation, IVF, ICSI and PA were performed as described previously [11-13].

The zonae pellucidae of expanded blastocysts (both in vivo- and in vitro-produced) was removed in $0.5 \%$ pronase solution, and the inner cell masses (ICM) were isolated mechanically by microdissection with two fine needles (G30). When the ICM was not visible (especially in IVP blastocysts or in a small number of in vivo blastocysts), the blastocysts were cut into two or three parts. Two or three isolated ICMs (or 4-6 sections of blastocysts) were seeded per well in 4-well plates (Nunc, Roskilde, Denmark) onto a monolayer of mitomycin $\mathrm{C}$-inactivated mouse embryonic fibroblast (MEF) cells. MEF cells were derived from fetuses of a CD1 mouse strain that were 11-13 days old, inactivated by $10 \mu \mathrm{g} / \mathrm{ml}$ mitomycin $\mathrm{C}$ for $2.5-3 \mathrm{~h}$ and stored in liquid nitrogen. Cultivation was performed in pES medium at $38.5 \mathrm{C}$ with $5 \% \mathrm{CO}_{2}$ in a humidified atmosphere. The pES medium consisted of KnockOut DMEM (Invitrogen) supplemented with $2 \mathrm{mM}$ L-glutamine, 0.1 mM 2-mercaptoethanol, $0.1 \mathrm{mM}$ MEM nonessential amino acids (Invitrogen), nucleosides $(0.03 \mathrm{mM}$ adenosine, $0.03 \mathrm{mM}$ guanosine, $0.03 \mathrm{mM}$ cytidine, $0.03 \mathrm{mM}$ uridine and $0.01 \mathrm{mM}$ thymidine), 1,000 IU/ml human recombinant leukemia inhibitory factor (LIF; Chemicon, Temecula, CA, USA), $10 \mathrm{ng} / \mathrm{ml}$ human recombinant basic fibroblast growth factor (bFGF; Invitrogen), 100 $\mathrm{IU} / \mathrm{ml}$ penicillin, $0.1 \mathrm{mg} / \mathrm{ml}$ streptomycin and $20 \%$ KnockOut Serum Replacement (KO-SR; Invitrogen). For the first 2-3 days of culture, $5 \%$ FBS was added to the pES medium. The growth and development of colonies from attached embryos was examined daily, and half of the medium was changed every second day.

Timing for the disaggregation of primary colonies was based on morphology and size. Cultures were passaged mechanically without enzymatic treatment. When a colony reached $3-5 \mathrm{~mm}$, it was individually peeled off from the feeder layer with the aid of two fine needles (G30), transferred to a drop of $\mathrm{pES}$ medium on a watch-glass and torn to small pieces under an Olympus SZXILLB2-200 stereomicroscope (Olympus, Tokyo, Japan). Pieces of colonies were transferred onto a new feeder layer with $400 \mu \mathrm{l}$ of fresh $\mathrm{pES}$ medium and $100 \mu \mathrm{l}$ of the conditioned $\mathrm{pES}$ medium used in the previous culture per well of a 4 -well plate. New colonies were subcultured at an interval of approximately 7-10 days, according to their size and growth rate.

\section{Embryoid body formation}

For embryoid body (EB) formation, colonies of porcine ES cells were cut into small pieces and cultured in hanging drops in $\mathrm{pES}$ medium without LIF for 10-14 days.

\section{Detection of alkaline phosphatase activity}

Expression of alkaline phosphatase (AP) activity in blastocystderived colonies was detected using an Alkaline Phosphatase Detection Kit (Chemicon), which stained AP-positive cells purplered, or SIGMAFAST ${ }^{\mathrm{TM}}$ Fast Red TR/Naphthol AS-MX Tablets, which stained AP-positive cells bright red. Mouse ES cells (CGR8) were stained as a positive control for AP activity. Negative cells were colorless after staining.

\section{Indirect immunofluorescence}

For immunocytochemical analysis, cell colonies were grown on rounded cover glasses (12 mm; Marienfeld $\mathrm{GmbH}$, Germany) that were covered with MEF. Before immunostaining, zona-free blastocysts or glasses with attached colonies were washed with PBS and fixed in 4\% paraformaldehyde for $10 \mathrm{~min}$ at RT, rinsed with PBS, permeabilized in $0.2 \%$ Triton $\mathrm{X}-100$ in PBS for $10 \mathrm{~min}$, washed three times in PBS/BSA (PBS $+0.5 \%$ bovine serum albumin) and incubated for $1 \mathrm{~h}$ in a blocking solution (consisting of 5\% serum of the same animal species from which the secondary antibody was derived). Cells were incubated overnight with the primary antibody (4 C). The primary antibodies used were as follows: goat polyclonal anti-OCT-3/4 (1:50, clone N19, sc-8628; Santa Cruz Biotechnology, Santa Cruz, CA, USA), mouse monoclonal antihuman GATA-4 (1:100, sc-25310; Santa Cruz Biotechnology), mouse monoclonal anti- $\beta$ III TUBULIN (1:100, MAB5544, clone TUJ1; Chemicon), mouse monoclonal anti-GFAP (glial fibrillary acidic protein; 1:100, 11-255-C100; Exbio, Praha, Czech Republic), mouse monoclonal anti-human AFP ( $\alpha$-fetoprotein, 1:100, 11259-C100; Exbio), mouse monoclonal anti-CK18 (cytokeratin 18, 1:100, 11-106-C100; Exbio), mouse monoclonal anti-TRANSFERRIN (1:100, 11-258-C100; Exbio), mouse monoclonal antiVIMENTIN (1:100, 11-254-C100; Exbio), mouse monoclonal anti-NF-M (neurofilament medium protein, 1:100, 11-294-C100; Exbio), mouse monoclonal anti-NF-H (neurofilament heavy protein, 1:100; 11-256-C100; Exbio), rabbit polyclonal anti-NANOG (1:50, ab21603; Abcam, Cambridge, UK) and mouse monoclonal anti-LAMINS A/C (1:10, clone JoL3, ab4789; Abcam). In addition to the antibodies mentioned above, we list antibodies that we have found not to react specifically with porcine epitope - goat polyclonal anti-NANOG (NB110-40660; Novus Biologicals, Inc, Littleton, CO, USA), mouse monoclonal anti-TRA-1-60 and mouse 
monoclonal anti-TRA-1-81 (both from ES Cell Characterization Kit CSR001; Chemicon), mouse monoclonal anti-SOX2 (MAB2018; R\&D Systems, Minneapolis, MN, USA), mouse monoclonal anti- $\beta$ III TUBULIN (11-264-C100; Exbio), rabbit polyclonal anti-OCT-4 (NB110-85544; Novus Biologicals), mouse monoclonal anti-OCT-4 (MAB4305; Chemicon), mouse monoclonal anti-OCT-3/4 (sc-5279; Santa Cruz Biotechnology) and goat polyclonal anti-OCT-3/4 (sc-8629; Santa Cruz Biotechnology).

Fluorescein isothiocyanate (FITC; Molecular probes, Eugene, OR, USA) conjugated antibodies (1:100-300, $1 \mathrm{~h}, \mathrm{RT})$ were used for visualization of antigens. To visualize all DNA material, cells were mounted on slides in SlowFade Gold antifade reagent (Invitrogen). Fluorescence was evaluated under an Olympus BX 61TRF fluorescent microscope (Olympus) equipped with a DP30BW CCD camera (Olympus). Images were processed in image analysis software (Olympus).

\section{Reverse-transcription polymerase chain reaction (RT-PCR)}

RNA was isolated using the 6100 nucleic acid prepStation (Applied Biosystems, Foster City, CA, USA) according to the manufacturer's instructions. Contaminations were removed using absolute RNA wash solution (Applied Biosystems). Synthesis of cDNA was carried by RT-PCR using a High Capacity cDNA Reverse Transcription kit (Applied Biosystems) with random primers. PCR was run in a $\mathrm{T}$ gradient thermocycler (Biometra, Göttingen, Germany) using a program consisting of a first step at $95 \mathrm{C}$ for $5 \mathrm{~min}$ followed by 35 repetitions of denaturation (95 C, 2 $\mathrm{sec})$, annealing ( $30 \mathrm{sec})$ and amplification ( $72 \mathrm{C}, 1 \mathrm{~min})$. The annealing temperature was set at $65 \mathrm{C}$ for $N A N O G$ and $58 \mathrm{C}$ for the $O C T-4$ and HPRT genes. Porcine OCT-4, NANOG and HPRT were amplified by PCR with the following primers: 5'-AGG TGT TCA GCC AAA CGA CC-3' and 5'-TGA TCG TTT GCC CTT CTG GC-3' for porcine OCT-4 [14], 5'-ATC CAG CTT GTC CCC AAA G-3' and 5'-ATT TCA TTC GCT GGT TCT GG-3' for NANOG [14] and 5'-CCA GTA AAC GGG CGA TAT AA-3' and 5'-CTT GAC CAA GGA AAG CAA GG-3' for HPRT [15]. HPRT was used as a normalization gene. A negative control was run without reverse transcriptase to estimate the contamination by genomic DNA. PCR products were separated on $2 \%$ agarose gels and detected using ethidium bromide.

\section{Telomerase-specific mRNA expression}

Five to ten blastocysts or cultured embryo-derived cell colonies were washed in PBS and stored in a small volume of PBS in liquid nitrogen. RNA isolation, cDNA transcription and telomerase mRNA expression (TERT) assessment were accomplished according to the method previously described by Tomanek et al. [16]. This method was patented by The Czech Industrial Property Office [17].

\section{Cytogenetic analysis}

Karyotypes were generated using the modified method described by Verma et al. [18]. Adherent cells were arrested in metaphase by the treatment with $0.5 \mu \mathrm{g} / \mathrm{ml}$ colcemid for $1 \mathrm{~h}$ at 38.5 C. The cultures were then trypsinized and resuspended in a hypotonic solution $(75 \mathrm{mM} \mathrm{KCl})$ for $30 \mathrm{~min}$. Cells were pelleted and fixed three times in glacial acetic acid/methanol (1:3). Metaphase spreads were prepared by dropping the cells onto clean microscope slides. Just before drying out, slides were immersed for $2 \mathrm{sec}$ in a $50 \%$ acetic acid solution and allowed to dry out on a heating plate (37 C). Slides were mounted in Mowiol/DAPI and inspected under an Olympus BX 61 fluorescent microscope using oil immersion.

DNA FISH was performed according to previously published protocols [19]. Briefly, cells were fixed in 4\% paraformaldehyde in PBS, permeabilized in $0.5 \%$ Triton X-100 in PBS, soaked in $20 \%$ glycerol and frozen/thawed in liquid nitrogen for four times. Thereafter, the cells were washed in PBS and incubated in $0.1 \mathrm{M}$ $\mathrm{HCl}$ and pepsin $(0.01 \% \mathrm{HCl} / 0.002 \%$ pepsin $)$. Star*FISH Porcine $\mathrm{X} / \mathrm{Y}$ Paints (Cambio, Cambridge, UK) were used to determine the presence of the sex chromosomes of the cell lines. The cells were codenatured with the probes at $80 \mathrm{C}$. Slides were washed in $2 \times \mathrm{SSC}$ at $37 \mathrm{C}, 0.1 \times \mathrm{SSC}$ at $60 \mathrm{C}$ and $4 \times \mathrm{SSC} / 0.2 \%$ Tween- 20 at room temperature. The slides were mounted in VECTASHIELD mounting medium supplemented with DAPI (Vector Laboratories, Peterborough, UK) and observed under an Olympus BX 61TRF fluorescent microscope (Olympus).

\section{Results}

\section{Cell lines from in vivo-obtained blastocysts}

The blastocysts flushed from the uteri of mated gilts were of high quality, even when they were flushed as morulae or early blastocysts, and were maintained in M199 + 10\% FBS until they progressed to expanded or hatched blastocysts. In spite of OCT-4 staining being uniform in both the ICM and trophectoderm (Fig. 1b), the ICM cells were distinguishable from trophectoderm cells under a phase contrast microscope (Fig. 1c). Hence, in most cases, we isolated ICMs microsurgically and seeded them onto a feeder layer. Attachment and colony formation were observed approximately 1-2 and 3-4 days after the initiation of culture, respectively. Out of 21 pig ICMs, 12 ICMs (57.1\%) attached to the feeder layer, and 7 attached ICMs (33.3\%) started to grow. After seeding the ICM onto the feeder layer, three cell types were observed (Fig. 2): (i) densely packed colonies of round to oval cells with a high nucleus/cytoplasm ratio and prominent nucleoli, which formed monolayers with distinct colony borders resembling human ES cells, called ES-like cells; (ii) larger, polyhedral-shaped cells with obvious cell and colony borders growing in more flattened monolayers, called epithelial-like cells; and (iii) large, polyhedral-shaped spread cells with abundant lipid droplets in their cytoplasm and large intracellular areas, called trophectoderm cells. We attempted to passage ES-like cells onto a new feeder layer. Colonies from two blastocysts $(9.5 \%)$ survived passage 1 with unchanged morphology; however, after subsequent passaging, most of the ES-like cells differentiated into cells with epithelial-like morphology. We were able to maintain one of these cell lines in culture up to passage 14 (Table 1).

ICM outgrowths at passage 0 were assayed by RT-PCR for the expression of genes related to pluripotency. These cells exhibited relatively robust expression of $O C T-4$ and $N A N O G$ (Fig. 3). After passage 1, the $O C T-4$ expression mostly disappeared, even in colonies with ES-like morphology, whereas the expression of NANOG 

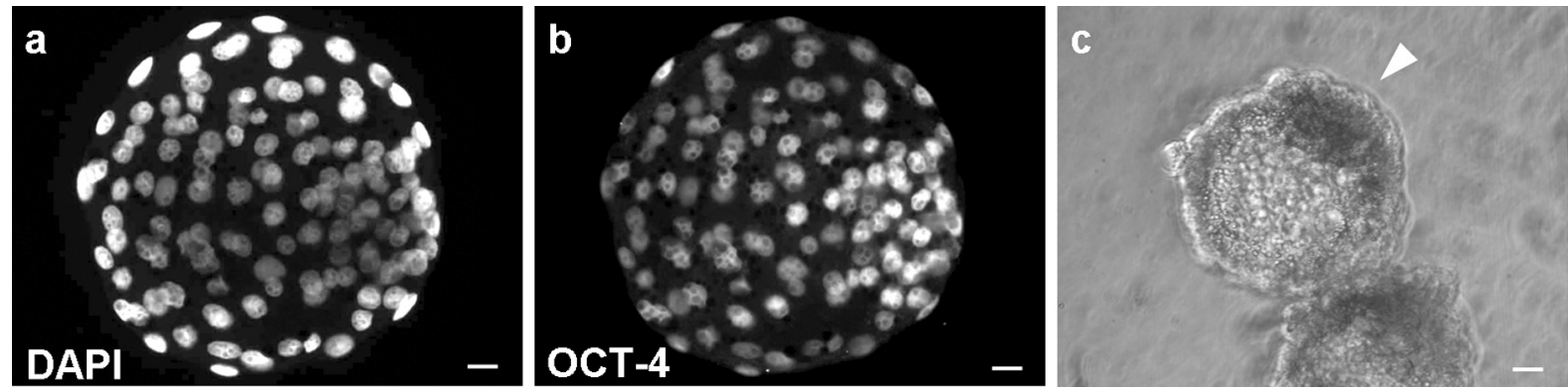

Fig. 1. The inner cell mass visualization of blastocysts obtained in vivo. (a) Visualization of DNA by DAPI. (b) Immunofluorescent detection of OCT-4 does not distinguish the ICM from trophectoderm. (c) The ICM (arrowhead) is obvious under a phase contrast microscope. $\mathrm{Bar}=50 \mu \mathrm{m}$.
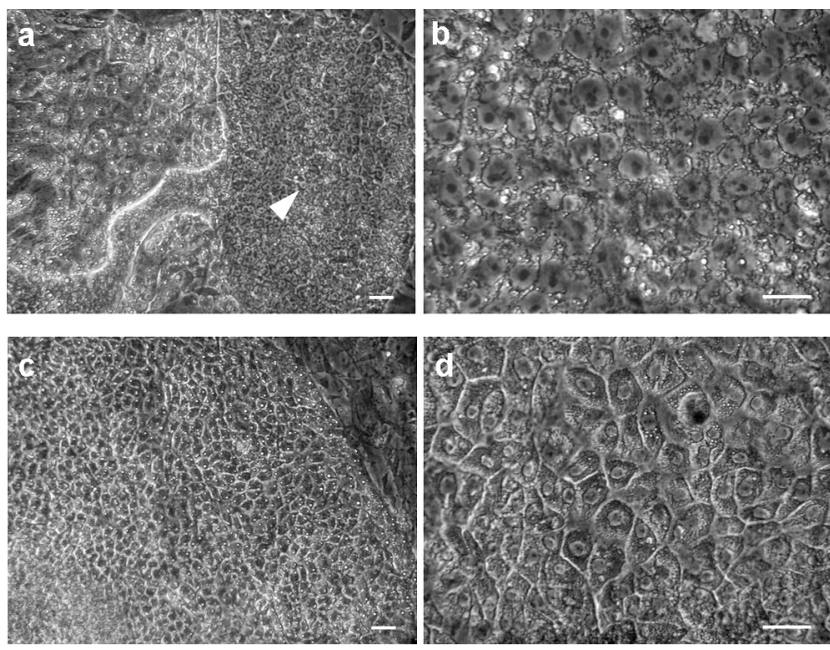

Fig. 2. Three types of colonies formed after seeding porcine in vivo blastocysts onto a feeder layer. (a) ES-like cells (arrowhead), (b) ES-like cells-high magnification, (c) epithelial-like cells and (d) trophectoderm cells. Bar $=50 \mu \mathrm{m}$.

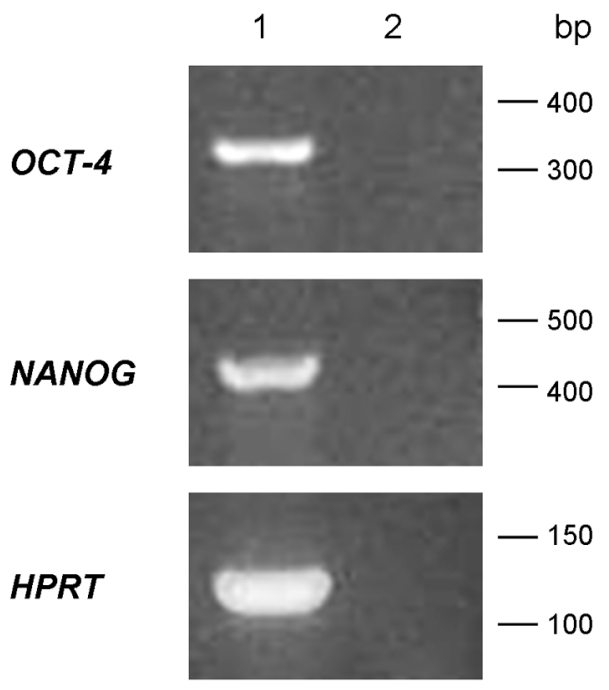

Fig. 3. $O C T-4, N A N O G$ and HPRT mRNA expression in outgrowths derived from in vivo-produced porcine blastocysts. PCR products visualized in gel by ethidium bromide. Line 1 - passage 0 , line 2 -negative control.

Table 1. The number of embryo-derived cell lines isolated from different types of porcine blastocysts

\begin{tabular}{|c|c|c|c|c|c|c|}
\hline \multirow{2}{*}{\multicolumn{2}{|c|}{ Type of blastocyst }} & \multicolumn{2}{|c|}{ No. of blastocysts } & \multirow{2}{*}{$\begin{array}{c}\text { No. of primary } \\
\text { outgrowths }\end{array}$} & \multirow{2}{*}{$\begin{array}{l}\text { No. of cell lines } \\
\text { after } 1 \text { st passage }\end{array}$} & \multirow{2}{*}{$\begin{array}{l}\text { Max number } \\
\text { of passages }\end{array}$} \\
\hline & & $\overline{\text { Plated }}$ & Attached & & & \\
\hline In vivo & & 21 & $12(57.1 \%)$ & $7(33.3 \%)$ & $2(9.5 \%)$ & 14 \\
\hline \multirow[t]{4}{*}{ In vitro } & Total & 130 & $32(24.6 \%)$ & $9 \quad(6.9 \%)$ & $3(2.3 \%)$ & \\
\hline & $-\mathrm{PA}$ & 35 & $4(11.4 \%)$ & $3 \quad(8.6 \%)$ & 0 & 0 \\
\hline & - IVF & 31 & $14(45.2 \%)$ & $5(16.1 \%)$ & $2(6.5 \%)$ & 12 \\
\hline & - ICSI & 64 & $14(21.9 \%)$ & $1 \quad(1.6 \%)$ & $1(1.6 \%)$ & 9 \\
\hline
\end{tabular}

was detected even at the passage 12 (not shown). Cytochemical staining showed that ES-like cells at passage 0 revealed OCT-4, AP (Fig. 4a, f) and NANOG (not shown) expression and lacked markers of differentiation (LAMINS A/C and CK18; not shown). After passaging, cell lines expressed NANOG (Fig. 4b) and exhibited weak AP staining (Fig. 4g), but unlike murine ES cells, they also exhibited expression of nuclear CK18, LAMINS A/C, GATA-4
(Fig. 4c-e) and TRANSFERRIN (not shown), which are markers associated with differentiation. These cells were negative for markers of neural differentiation (VIMENTIN, $\beta$ III TUBULIN, NF-H and NF-M; not shown). Moreover, these already differentiated cells were able to form spherical formations, which resemble embryoid bodies morphologically (Fig. 5a). These formations, which we named embryoid bodies-like structures, appeared 

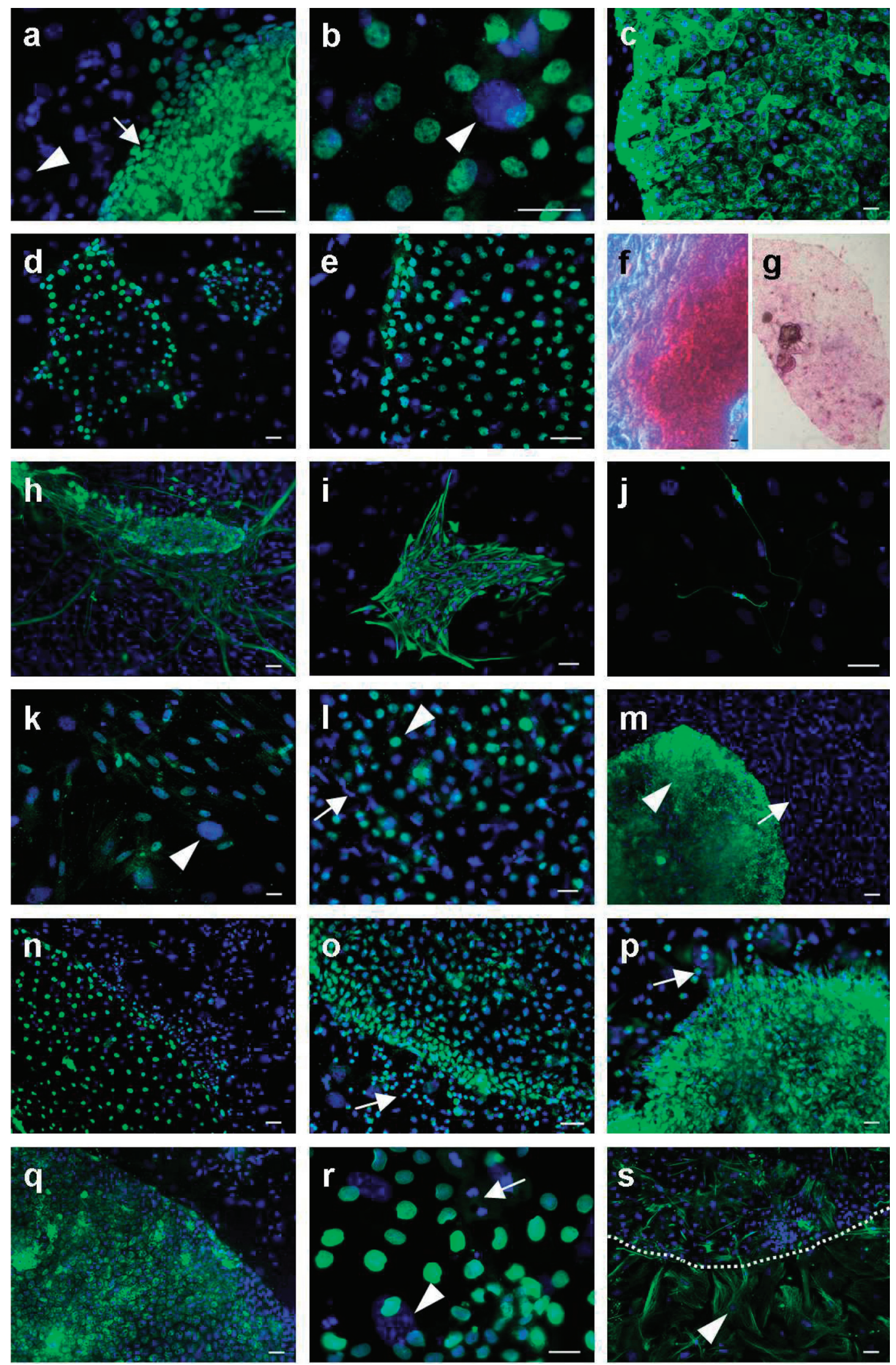

Fig. 4. 
Fig. 4. Immunocytochemical detection of antigens in porcine cell lines derived from in vivo (a-g), ICSI (h-m) and IVF ( $\mathrm{n}-\mathrm{s})$ blastocysts. (a) OCT-4 (arrowhead-epithelial-like cell, arrow-ES-like cell colony), (b, k, o) NANOG (arrowhead - feeder cell, arrow- separated single cell), (c, m) CK18 (arrowhead — colony of epithelial-like cells, arrow—neural-like outgrowth), (d, r) LAMINS A/C (arrowhead—mouse feeder cell, arrowdividing cell), (e, l, n) GATA-4 (arrow—elongated neural-like cell, arrowhead - epithelial-like cell), (h) $\beta$ III TUBULIN, (i) GFAP, (j) NF-H, (p) AFP (arrow-separated single cell), absence of (q) TRANSFERRIN and (s) VIMENTIN in a colony of epithelial-like cells (spotted white linecolony border, arrowhead - feeder cell), (f, g) alkaline phosphatase staining, (a, f) detection at passage 0, (b-e, g-s) detection at passages 2-7. $\mathrm{Bar}=20 \mu \mathrm{m}$, (g) documented by stereomicroscope with approximately 8.5 -fold magnification.
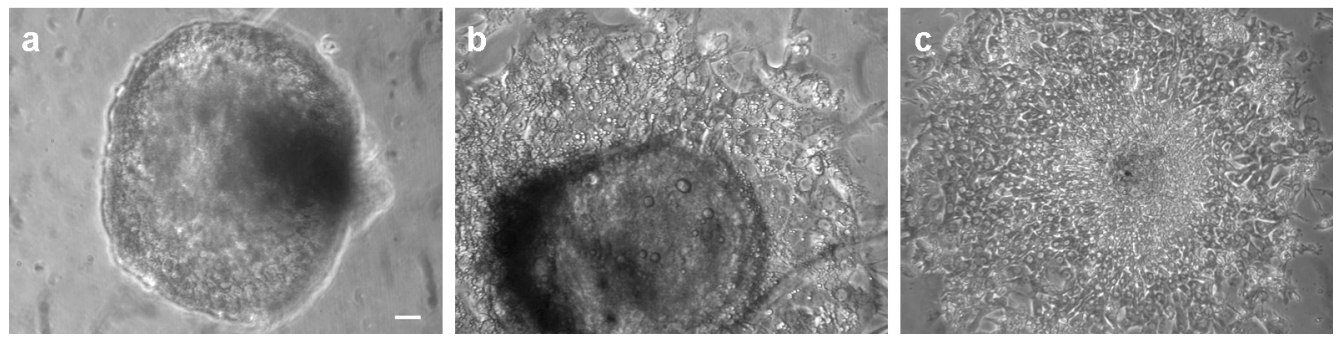

Fig. 5. Embryoid body-like structures formed from epithelial-like cells. EB-like structures grown in hanging drops for five days (a) were further cultivated as an adherent culture for three (b) and seven days (c). bar $=50 \mu \mathrm{m}$.
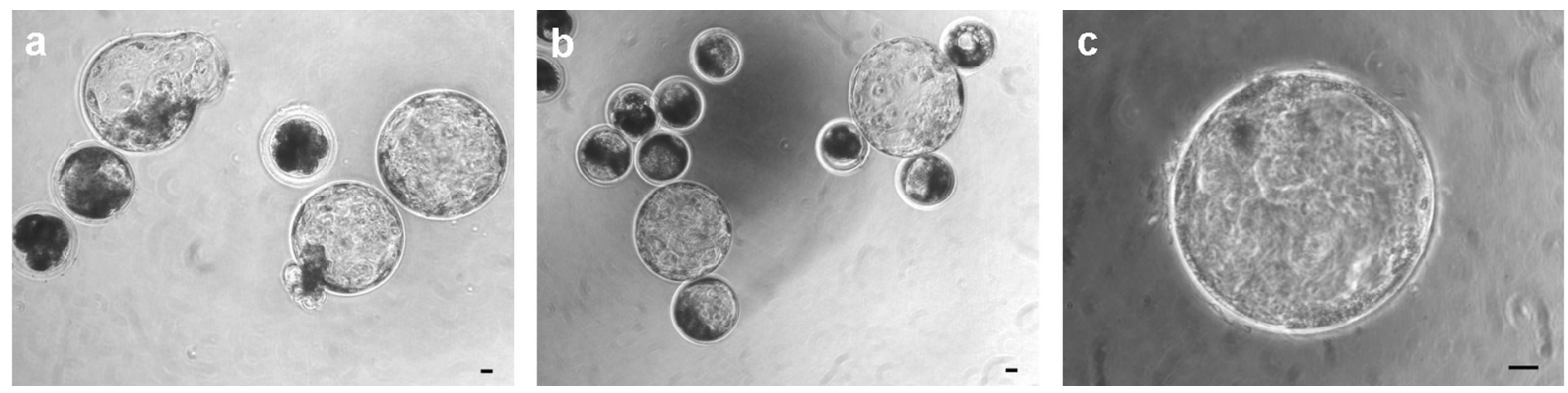

Fig. 6. In vitro-derived blastocysts after (a) in vitro fertilization, (b) parthenogenetic activation and (c) intracytoplasmic sperm injection. $\mathrm{Bar}=50 \mu \mathrm{m}$.

approximately five days after culture of epithelial-like cells in hanging drops in a medium without LIF. When seeded back onto gelatinized culture dishes, they attached to the surface and started to grow in a monolayer (Fig. 5b, c).

\section{Cell lines from in vitro-produced blastocysts}

In vitro-produced blastocysts were obtained from in vitromatured oocytes following PA, IVF and ICSI. These blastocysts exhibited low cell numbers $[11,20]$, and the ICM was indistinct in most cases under a stereomicroscope (Fig. 6). As was observed in the in vivo blastocysts, OCT-4 staining did not distinguish the ICM from the trophectoderm (Fig. 7). For this reason, we were not sure whether blastocysts contained no ICM or if the ICM consisted of only a few cells. For seeding onto a feeder layer, we used 130 IVP blastocysts (35 PA, 31 IVF and 64 ICSI) seven days after fertilization or parthenogenetic activation. We only used expanded or hatched blastocysts. The zona pellucida was removed from expanded blastocysts by pronase treatment. To avoid floating of whole blastocysts in culture medium and to enable better attach- ment to the feeder layer, we cut the blastocysts into two or three parts. In total, 32 blastocysts $(24.6 \%)$ attached to the feeder layer after 24-48 h (Table 1). Part of attached pieces of blastocysts created vesicle-like structures at their edges and started to grow. Nine blastocysts $(6.9 \%)$ created colonies; colonies that survived passage 1 originated from three blastocysts $(2.3 \%)$. Most of the colonies were composed of trophectoderm or epithelial-like cells (Fig. 8).

After seeding of 35 PA blastocysts, 4 blastocysts (11.4\%) attached and created three colonies (8.6\%), one epithelial-like and two trophectoderm colonies, which did not survive the first passage. One cell line (1.6\%) was derived from 14 attached $(21.9 \%)$ ICSI-derived blastocysts and survived 9 passages. Two cell lines (6.5\%) were derived from 14 attached (45.2\%) IVF-derived blastocysts. These cell lines survived 5 and 12 passages, respectively. Cells of the colony derived from an ICSI blastocyst spontaneously differentiated into neural-like cells (Fig. 8). The neural-like cells were positive for $\beta$ III TUBULIN, GFAP, NF-H and NANOG and negative for GATA-4, CK18 (Fig. 4h-m) and OCT-4 (not shown). GATA-4 and CK18 were found in epithelial-like cells (Fig. 41, m), 
which were negative for the neural markers ( $\beta$ III TUBULIN, GFAP, NF-H; not shown). After passage 4, the neural-like cells gradually slowed their division rate until their proliferation potential was completely restricted. Epithelial-like cells started to grow
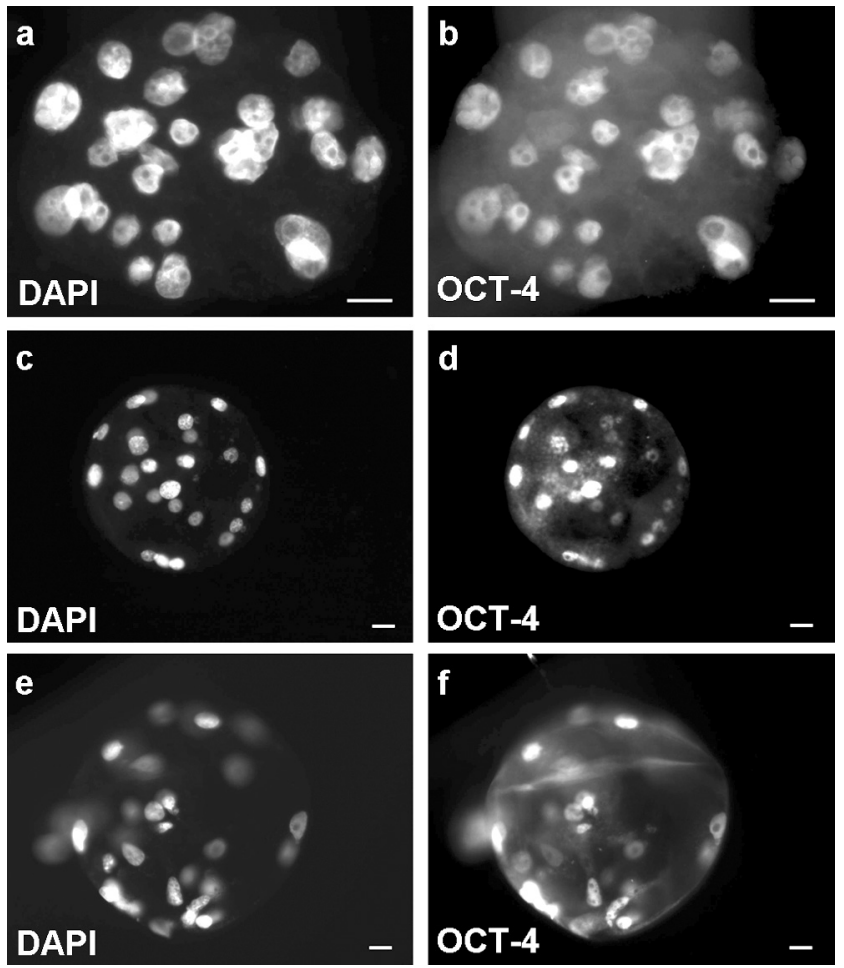

Fig. 7. OCT-4 immunodetection in blastocysts derived in vitro. (a, b) IVF-produced blastocyst, (c, d) PA-produced blastocyst and (e, f) ICSI-produced blastocyst. Cell nuclei visualized by DAPI (a, c, e). Bar $=20 \mu \mathrm{m}$. immediately after passaging, and some of them differentiated into neural-like cells.

The two lines derived from IVF blastocysts survived 2 and 6.5 months in culture. Their colonies were initially formed of irregular cuboidal cells with distinct borders between them (epithelial-like). After passaging, several colonies differentiated into fibroblast-like cells or separated single detached or semidetached cells that grew out from the central part of the colony. Cells from several colonies formed particularly large lipid droplets in their cytoplasm; other colonies formed bulging aggregates of cells. However, the majority of cells exhibited a trophectoderm or epithelial-like morphology. When cells were cultivated in the medium used for MEF (DMEM high glucose, $2 \mathrm{mM}$ L-glutamine, $100 \mathrm{IU} / \mathrm{ml}$ penicillin, $0.1 \mathrm{mg} / \mathrm{ml}$ streptomycin, $0.1 \mathrm{mM}$ 2-mercaptoethanol and $10 \%$ FBS); they formed fibroblast-like cells (Fig. 8). Immunocytochemical staining showed that the IVF blastocyst-derived cell lines were positive for GATA-4, NANOG, AFP, TRANSFERRIN, LAMINS A/C (Fig. 4n-r) and CK18 (not shown). Part of the colonies retained weak AP staining (not shown). However, VIMENTIN (Fig. 4s), $\beta$ III TUBULIN, NF-M, GFAP and OCT-4 (not shown) were not found in these cell lines.

We compared the effect of passaging by mechanical dissection with $0.25 \%$ trypsin/EDTA (Invitrogen) treatment in colonies derived from both in vitro and in vivo-obtained blastocysts. We were able to successfully passage our cell lines only by mechanical dissection without enzymatic treatment (11 months in culture).

\section{Telomerase $m R N A$ expression}

The highest telomerase mRNA expression was found in in vivo blastocysts $(48.7 \pm 10.3$ relative units - r.u. $)$. The level of porcine TERT found in IVP blastocysts (ICSI, PA) was also relatively high (37.0 \pm 6.3 r.u., $24.4 \pm 4.8$ r.u., respectively; Fig. 9), though it was lower than in in vivo blastocysts. Data were obtained from 2-3 independent experiments including 5-10 blastocysts per sample. Data obtained from passaged cell lines (one cell culture per condi-
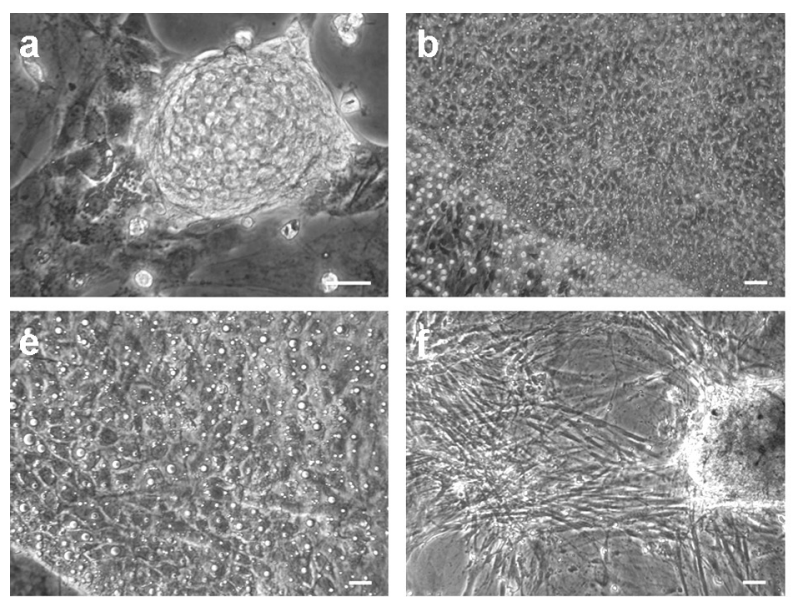
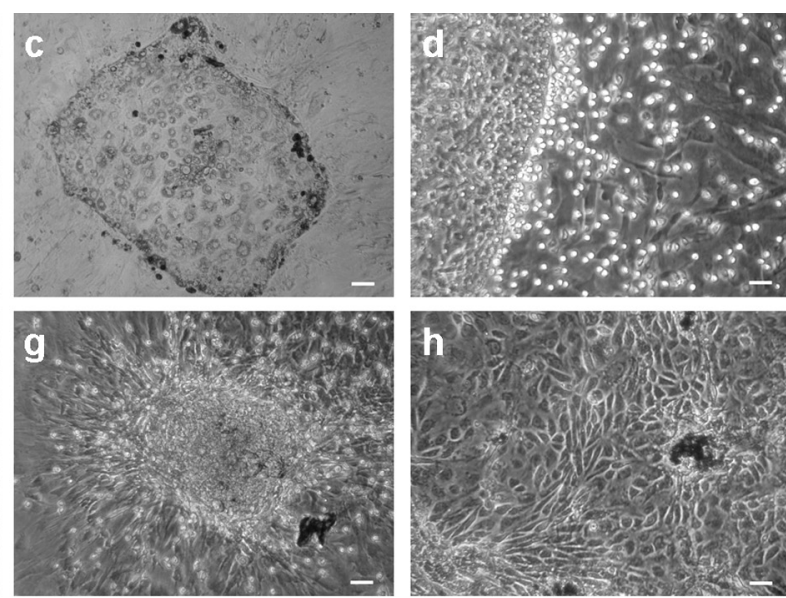

Fig. 8. Different cell type morphology of colonies derived from in vitro-produced blastocysts. (a) Colony of bulging aggregates of cells, (b) epithelial-like cells, (c) trophectoderm cells, (d) separated single detached or semidetached cells, (e) epithelial-like cells with large lipid droplets, (f) neural-like cells, (g) fibroblast-like cells growing up from the colony and (h) fibroblast-like cells cultivated in medium with $10 \%$ FBS. Bars $=50 \mu \mathrm{m}$. 


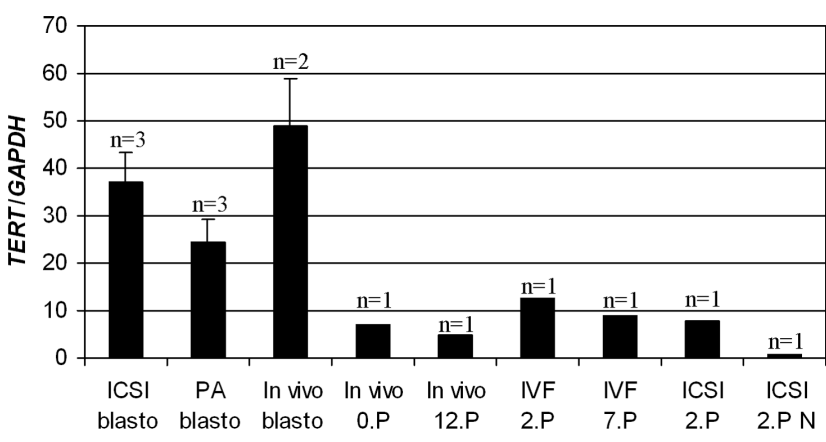

Fig. 9. Telomerase mRNA expression (TERT) measured in porcine in vitro- and in vivo-derived blastocysts and in colonies cultured in vitro at different passages (expressed in relative units; $\mathrm{n}$ number of independent experiments proceeded for each condition; blasto — blastocysts; $\mathrm{P}$-passage number; $\mathrm{N}$ differentiated neural-like cells; GAPDH-glyceraldehyde 3phosphate dehydrogenase, a reference gene). Due to the restricted number of cell lines derived, results could not be validated statistically.

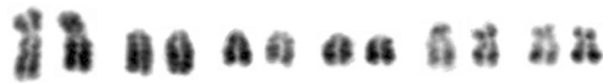

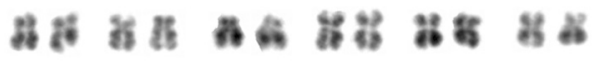

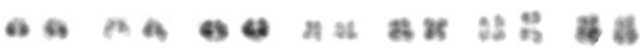

Fig. 10. Cytogenetic analysis of an in vivo blastocyst-derived cell line (passage 4; $36 \mathrm{XX}$ chromosomes).

tion) suggested a considerable decrease of telomerase mRNA expression during cell cultivation and differentiation of the ICSIderived cell line into neural-like cells.

\section{Cytogenetic analysis of cell lines}

Karyotype and FISH analyses revealed that cell lines derived from blastocysts after ICSI at passage 2 and from IVF at passage 6 possessed a normal chromosome number (36 XX and $36 \mathrm{XY}$, respectively; not shown). In addition, the cell line derived from in vivo blastocyst also exhibited a normal chromosome number (36 $\mathrm{XX}$ ) at passage 4 (Fig. 10).

\section{Discussion}

The present study was undertaken to characterize and compare the ability of IVP and in vivo-produced porcine blastocysts to establish ES cell lines. These cell lines were extensively characterized not only based on morphology and AP staining but also by the expression of markers of pluripotency and differentiation including telomerase mRNA expression.

Differences in the attachment and colony outgrowth between the in vivo and IVP blastocysts were obvious. More than $57 \%$ of the ICMs from in vivo-derived blastocysts attached, and more than
$33 \%$ started to grow. In our opinion, the lower capability of the IVP blastocysts to form primary culture outgrowths $(6.9 \%)$ was caused by lower quality of embryos following PA, IVF and ISCI. Additionally, the lower percentage of attachment of these embryos after seeding (24.6\%) might be due to a decreased ability of cut pieces of blastocysts to settle to the bottom of the culture dish. Because of the indistinct ICMs in most IVP blastocysts, we split embryos into two or three parts before seeding. The split pieces of blastocysts had the tendency to aggregate into blastocyst-like structures and to float in the medium, which decreased the possibility of their attachment. KO-SR, which was used in our culture system, is known not to support cell adhesion [21] due to the lack of specific attachment factors found in FBS. Therefore, to improve the attachment rate, we added 5\% FBS to the pES medium with KO-SR for the first 2-3 days of culture.

Of the different types of blastocysts investigated, we were able to derive cell lines only from in vivo (two cell lines), IVF (two cell lines) and ICSI blastocysts (one cell line). Only Brevini et al. [22] has thus far been successful in deriving stem cell lines from porcine PA embryos.

Initially, particular morphology was used as one of the criteria for the identification of porcine ES cell cultures. Most authors [7] described porcine ES cells as small rounded cells with large nuclei and nucleoli creating compact homogenous colonies. According to morphological criteria, our cell lines derived from in vivo blastocysts exhibited the ES-like characteristics at least before the first passage. Regardless of whether epithelial-like cells differentiated from ES-like cells or were the only cells found in blastocyst outgrowths, OCT-4 expression was lost, while the expression of NANOG and the activity of AP persisted in subsequent passages. In spite of NANOG expression and AP staining being observed, epithelial-like cells also expressed markers of differentiation (LAMINS A/C, CK18, GATA-4, AFP and TRANSFERRIN) that were not expressed in ES-like cells. It is possible that authors whose observations were based only on morphology and AP staining [7] could have misinterpreted their results because the morphology of ES-like, trophectoderm and endodermal cells may be confused [23], particularly shortly after passaging. Keefer et al. [23] did not recommend the use of the common marker of pluripotency, OCT-4, as a definitive marker for characterizing ungulate ES cells. In contrast to observations in mice and humans [24], OCT-4 is expressed not only in the ICM but also in the trophectoderm of porcine blastocysts. As a more suitable pluripotency marker, NANOG expression was recommended for identifying ES cells in ungulates [23]. However, we did not observe NANOG expression in porcine expanded or early hatched blastocysts, which was also confirmed by other authors [25-27]. Moreover, we observed NANOG expression in epithelial-like cells together with markers of differentiation. NANOG expression disappeared after the differentiation of cells into neural-like cells. Therefore, our results show that neither NANOG is a good marker for identifying porcine ES cells. We strongly recommend determination of differentiation markers in putative porcine ES cell lines. In particular, known markers of the visceral endoderm (AFP, TRANSFERRIN and GATA-6) and the trophectoderm (GATA-4, HAND1 and CDX2), $[26,28,29]$ as well as the epithelial cell marker CK18 [30] and the 
extraembryonic marker LAMINS A/C [31], should be examined to exclude the possibility that putative ES cells are not, in fact, trophectoderm or endoderm cells.

Another criterion used to identify porcine ES cells is the formation of embryoid bodies [32-34]. The authenticity of EBs should be verified not only by their morphology but also by expressing markers of all three germ layers. The creation of spherical structures resembling EBs was also observed in our study. Surprisingly, the EBs were produced from epithelial-like cells that expressed extraembryonic markers. This phenomenon was previously described by Keefer et al. [23], who presumed that the trophectoderm and endoderm, like other polarized or "dome-forming" epithelial cells, produce "embryoid-like" bodies if grown without attachment to a solid cell culture substrate.

The ability to differentiate into various cell types is another important feature of ES cells. We mainly observed spontaneous differentiation into epithelial-like cells, which was confirmed by the expression of AFP, TRANSFERRIN, CK18 and GATA-4. Some cells differentiated into neural or fibroblast-like cells. Neural-like cell differentiation was verified by marker expression (VIMENTIN, $\beta$ III TUBULIN, NF-M, NF-H and GFAP), and fibroblast-like cells were confirmed by morphology and VIMENTIN expression. Ultimately, all cells slowed down their proliferation and disappeared from culture.

We also evaluated the level of telomerase mRNA expression in porcine blastocysts and blastocyst-derived cell lines. It is commonly known that telomerase activity is present in germ cells, stem cells, tumor cells and most immortal cell lines. High levels of telomerase activity, a hallmark of mouse ES cells, were also found in porcine induced pluripotent stem cell lines [35]. We found relatively high levels of telomerase expression in both in vivo and in vitro-produced blastocysts. Relatively high levels of telomerase activity were previously described in porcine and bovine blastocysts derived in vitro and in vivo [36-38]. The samples used for telomerase expression assessment in our blastocyst-derived cell lines were collected during culture passaging. Telomerase expression was considerably reduced already at passage 0 , regardless of whether IVP or in vivo blastocysts were used for cell line derivation. These results correspond to the finding of Talbot and Blomberg [39], who showed that spontaneous differentiation occurs 48-72 $\mathrm{h}$ after plating of the porcine epiblast cell mass in culture. Decreasing activity of telomerase during differentiation of embryos in a tissue- and cell-specific manner was described previously [40]. We observed a trend in marked reduction of telomerase expression after differentiation of cells into neural-like cells.

We did not observe any chromosomal abnormality in our cell lines. We checked three cell lines derived from ICSI, IVF and in vivo blastocysts at the passages 2,6 and 4, respectively. In all cases, we observed 38 chromosomes; two cell lines were derived from female blastocysts, and one was derived from a male blastocyst.

Most putative porcine ES cell lines were established using in vivo-derived embryos. Although mice and human ES cell lines were also derived from IVP embryos [6, 41], little research has been done in other animal species. Moreover, the quality of IVP blastocysts derived from pigs is questionable. The porcine oocytes used for in vitro fertilization are, in most cases, obtained at slaughterhouses from immature crossbred gilts designated for meat production only. These oocytes have to be cultured for a prolonged period in maturation media before fertilization. Furthermore, a defined epiblast is not present in the pig blastocyst before hatching, whereas in mice, the epiblast is already formed in blastocysts enclosed in the zona pellucida [9]. Therefore, the ICM available in the prehatching porcine blastocyst may not be exactly equivalent to the mouse epiblast usually recovered for ES cell derivation [22]. Furthermore, the number of cells in IVP blastocysts and, in particular, in their ICMs is reduced compared with in vivo blastocysts [11]. The chance to establish ES cell lines from IVP blastocysts is reduced because the number of cells of the ICM is assumed to be a factor that might affect the survival of porcine ICMs in culture [42]. In vivo-derived blastocysts might be a more suitable source of pluripotent cells, but their use as a starting material for isolating ES cells is expensive and laborious [9]. We were not able to derive authentic porcine ES cell lines from either in vitro- or in vivoderived blastocysts. It is possible that the expanded or just hatched blastocysts used for ES cell derivation were not developed enough in comparison with mice blastocysts of the same developmental stage. Older blastocysts (10-12 days) with well-developed epiblasts may be more suitable for porcine ES cell derivation [43]. Unfortunately, these blastocysts cannot be produced by in vitro culture conditions.

Based on the loss of OCT -4 expression and the expression of several differentiation markers, we can conclude that it is most likely either that our cell lines differentiated shortly after establishment or that faster growing epithelial cells overgrew pluripotent cells derived from the ICM. Although we were not able to maintain true ES cell lines in culture, we were able to produce blastocystderived cell lines that could grow in vitro for a prolonged period and could possibly be used for genetic manipulation in the pig. Nevertheless, in accordance with Munoz et al. [9], we confirmed that the combined use of morphological criteria and the analysis of extraembryonic markers is necessary to truly identify porcine ES cells and/or rule out the presence of trophectoderm or visceral endoderm cells in ES cell cultures.

\section{Acknowledgments}

The authors would like to thank A Ungrova for her technical assistance. This work was supported by grants 0002701404 and QI 101 A166 (Ministry of Agriculture of the Czech Republic) and 1M0538 (Ministry of Education, Youth and Sports of the Czech Republic).

\section{References}

1. Evans MJ, Kaufman MH. Isolation and culture of pluripotential cells from early mouse embryos. J Anat 1981; 133: 107-108.

2. Martin GR. Isolation of a pluripotent cell-line from early mouse embryos cultured in medium conditioned by teratocarcinoma stem-cells. Proc Natl Acad Sci USA 1981; 78: 7634-7638

3. Wobus AM, Boheler KR. Embryonic stem cells: Prospects for developmental biology and cell therapy. Physiol Rev 2005; 85: 635-678.

4. Li P, Tong C, Mehrian-Shai R, Jia L, Wu N, Yan Y, Maxson RE, Schulze EN, Song H, Hsieh CL, Pera MF, Ying QL. Germline competent embryonic stem cells derived from 
rat blastocysts. Cell 2008; 135: 1299-1310

5. Brevini TAL, Antonini S, Pennarossa G, Gandolfi F. Recent progress in embryonic stem cell research and its application in domestic species. Reprod Dom Animals Suppl 2008; 43: 193-199.

6. Thomson JA, Itskovitz-Eldor J, Shapiro SS, Waknitz MA, Swiergiel JJ, Marshall VS, Jones JM. Embryonic stem cell lines derived from human blastocysts. Science 1998; 282: $1145-1147$

7. Vackova I, Ungrova A, Lopes F. Putative embryonic stem cell lines from pig embryos. J Reprod Dev 2007; 53: 1137-1149.

8. Vassiliev I, Vassilieva S, Beebe LFS, Harrison SJ, MCIlfatrick SM, Nottle MB. In vitro and in vivo characterization of putative porcine embryonic stem cells. Cellular Reprogramming 2010; 12: 223-230.

9. Munoz M, Diez C, Caamano JN, Jouneau A, Hue I, Gomez E. Embryonic stem cells in cattle. Reprod Dom Animals 2008; 43: 32-37.

10. Vodicka P, Smetana K, Dvorankova B, Emerick T, Xu YZ, Ourednik J, Ourednik V, Motlik J. The miniature pig as an animal model in biomedical research. Ann NY Acad Sci 2005; 1049: 161-167.

11. Krylov V, Kren R, Okada K, Vackova I, Tlapakova T, Fulka J. Effect of protein supplement source on porcine oocyte maturation and subsequent embryonic development after parthenogenetic activation. Folia Biol 2005; 51: 29-33.

12. Vackova I, Kren R, Loi P, Krylov V, Fulka J. The absence of a DNA replication checkpoint in porcine zygotes. Zygote 2006; 14: 33-37.

13. Okada K, Palmieri C, Della Salda L, Vackova I. Viability, acrosome morphology and fertilizing capacity of boar spermatozoa treated with strontium chloride. Zygote 2008; 16: 49-56.

14. Carlin C, Davis D, Weiss M, Schultz B, Troyer D. Expression of early transcription factors, Oct-4, Sox-2 and Nanog by porcine umbilical cord (PUC) matrix cells. Reprod Biol Endocrinol 2006; 4: 8 .

15. Dyce PW, Zhu H, Craig J, Li J. Stem cells with multilineage potential derived from porcine skin. Biochem Biophys Res Commun 2004; 316: 651-658

16. Tomanek M, Kott T, Chronowska E, Kottova E. Telomerase (pTERT) mRNA expression in the pig granulosa cells in vitro. In: Abstrakt Book of Society of Reproduction and Fertility's Annual Conference; 2008; Edinburgh, UK.

17. Kott T, Tomanek M, Kottova E, Chronowska E. The manner of porcine telomerase expression detection. Institute of Animal Science, 2008. Industrial Property Office, Czech Republic. Patent number P 299220 (In Czech).

18. Verma V, Gautam SK, Singh B, Manik RS, Palta P, Singla SK, Goswami SL, Chauhan MS. Isolation and characterization of embryonic stem cell-like cells from in vitroproduced buffalo (Bubalus bubalis) embryos. Mol Reprod Dev 2007; 74: 520-529.

19. Beatty B, Mai S, Squire J. FISH: A Practical Approach. Oxford University Press, Oxford, UK; 2002: 274.

20. Okada K, Krylov V, Kren R, Fulka J. Development of pig embryos after electroactivation and in vitro fertilization in PZM-3 or PZM supplemented with fetal bovine serum. J Reprod Dev 2006; 52: 91-98.

21. Goldsborough MD, Tilkins ML, Price PJ, Lobo-Alfonso J, Kortison JR, Stevens ME, Meneses J, Pedersen R, Koller B and Latou A. Serum free culture of murine embryonic stem (ES) cells. Focus 1998; 20: 8-12.

22. Brevini TAL, Tosetti V, Crestan M, Antonini S, Gandolfi F. Derivation and characterization of pluripotent cell lines from pig embryos of different origins. Theriogenology 2007; 67: 54-63.

23. Keefer CL, Pant D, Blomberg L, Talbot NC. Challenges and prospects for the establishment of embryonic stem cell lines of domesticated ungulates. Anim Reprod Sci 2007; 98: 147-168

24. Hansis C, Grifo JA, Krey LC. Oct-4 expression in inner cell mass and trophectoderm of human blastocysts. Mol Hum Reprod 2000; 6: 999-1004.

25. Kirchhof N, Carnwath JW, Lemme E, Anastassiadis K, Scholer H, Niemann H. Expression pattern of Oct- 4 in preimplantation embryos of different species. Bio Reprod 2000; 63: 1698-1705.

26. Kuijk EW, Du Puy L, Van Tol HTA, Oei CHY, Haagsman HP, Colenbrander B Roelen BAJ. Differences in early lineage segregation between mammals. Dev Dyn 2008; 237: 918-927.

27. Hall VJ, Christensen J, Gao Y, Schmidt MH, Hyttel P. Porcine pluripotency cell signaling develops from the inner cell mass to the epiblast during early development. Dev Dynam 2009; 238: 2014-2024.

28. Talbot NC, Caperna TJ, Edwards JL, Garrett W, Wells KD, Ealy AD. Bovine blastocyst-derived trophectoderm and endoderm cell cultures: Interferon tau and transferrin expression as respective in vitro markers. Biol Reprod 2000; 62: 235-247.

29. Lee E, Lee SH, Kim S, Jeong YW, Kim JH, Koo OJ, Park SM, Hashem MA, Hossein MS, Son HY, Lee CK, Hwang WS, Kang SK, Lee BC. Analysis of nuclear reprogramming in cloned miniature pig embryos by expression of Oct-4 and Oct-4 related genes. Biochem Biophys Res Commun 2006; 348: 1419-1428.

30. Miyazawa K, Hondo T, Kanaya T, Tanaka S, Takakura I, Itani W, Rose MT, Kitazawa H, Yamaguchi T, Aso H. Characterization of newly established bovine intestinal epithelial cell line. Histochem Cell Biol 2010; 133: 125-134.

31. Constantinescu D, Gray HL, Sammak PJ, Schatten GP, Csoka AB. Lamin A/C expression is a marker of mouse and human embryonic stem cell differentiation. Stem Cells 2006; 24: 177-185.

32. Evans MJ, Notarianni E, Laurie S, Moor RM. Derivation and preliminary characterization of pluripotent cell-lined from porcine and bovine blastocysts. Theriogenology 1990; 33: 125-128.

33. Kim HS, Son HY, Kim S, Lee GS, Park CH, Kang SK, Lee BC, Hwang WS, Lee CK Isolation and initial culture of porcine inner cell masses derived from in vitroproduced blastocysts. Zygote 2000; 15: 55-63.

34. Li M, Li YH, Hou Y, Sun XF, Sun QY, Wang WH. Isolation and culture of pluripoten cells from in vitro produced porcine embryos. Zygote 2004; 2: 43-48.

35. Ezashi T, Telugu BPVL, Alexenko AP, Sachdev S, Sinha S, Roberts RM. Derivation of induced pluripotent stem cells from pig somatic cells. Proc Natl Acad Sci USA 2009; 106: 10993-10998.

36. Betts DH, King WA. Telomerase activity and telomere detection during early bovine development. Dev Genet 1999; 25: 397-403.

37. Xu J, Yang XZ. Telomerase activity in early bovine embryos derived from parthenogenetic activation and nuclear transfer. Biol Reprod 2001; 64: 770-774.

38. Jeon HY, Hyun SH, Lee GS, Kim HS, Jeong YW, Kang SK, Lee BC, Han JY, Ahn C, Hwang WS. The analysis of telomere length and telomerase activity in cloned pigs and cows. Mol Reprod Dev 71; 2005: 315-320.

39. Talbot NC, Blomberg LA. The pursuit of ES cell lines of domesticated ungulates. Sten Cell Rev 2008; 4: 235-254.

40. Eisenhauer KM, Gerstein RM, Chiu CP, Conti M, Hsueh AJ. Telomerase activity in female and male rat germ cells undergoing meiosis and in early embryos. Biol Reprod 1997; 56: 1120-1125.

41. Kawase E, Yamazaki Y, Yagi T, Yanagimachi R, Pedersen RA. Mouse embryonic stem (ES) cell lines established from neuronal cell-derived cloned blastocysts. Genesi 2000; 28: 156-163.

42. Anderson GB, Choi SJ, BonDurant RH. Surfoval of porcine inner cell masses in culture and after injection into blastocysts. Theriogenology 1994; 42: 204-212.

43. Alberio R, Croxall N, Allegrucci C. Pig epiblast stem cells depend on activin/noda signaling for pluripotency and self renewal. Stem Cells Dev 2010; 19: 1627-1636. 